Cahiers $d u$ MONDE RUSSE

\section{Cahiers du monde russe}

Russie - Empire russe - Union soviétique et États indépendants

$55 / 3-4 \mid 2014$

Varia

\title{
Serguei Tchougounnikov, Céline Trautmann-Waller, éds., Pëtr Bogatyrëv et les débuts du Cercle de Prague, Recherches ethnographiques et théâtrales
}

Michel Aucouturier

\section{(2) OpenEdition \\ Journals}

Édition électronique

URL : http://journals.openedition.org/monderusse/8138

DOI : $10.4000 /$ monderusse. 8138

ISSN : $1777-5388$

Éditeur

Éditions de l'EHESS

\section{Édition imprimée}

Date de publication : 1 juillet 2014

Pagination : 509-511

ISBN : 978-2-7132-2441-6

ISSN : $1252-6576$

Référence électronique

Michel Aucouturier, « Serguei Tchougounnikov, Céline Trautmann-Waller, éds., Pëtr Bogatyrëv et les débuts du Cercle de Prague, Recherches ethnographiques et théâtrales ", Cahiers du monde russe [En ligne], 55/3-4 | 2014, mis en ligne le 14 avril 2015, Consulté le 25 septembre 2020. URL : http:// journals.openedition.org/monderusse/8138; DOI : https://doi.org/10.4000/monderusse.8138

Ce document a été généré automatiquement le 25 septembre 2020.

(C) École des hautes études en sciences sociales 


\title{
Serguei Tchougounnikov, Céline Trautmann-Waller, éds., Pëtr Bogatyrëv et les débuts du Cercle de Prague, Recherches ethnographiques et théâtrales
}

\author{
Michel Aucouturier
}

\section{RÉFÉRENCE}

Serguei TCHOUGOUNNIKOV, Céline TRAUTMANN-WALLER, éds., Pëtr Bogatyrëv et les débuts du Cercle de Prague, Recherches ethnographiques et théâtrales, Paris :

Éd. Presses Sorbonne nouvelle, 2013, 275 p.

J'ai rencontré pour la première fois Pëtr Grigor'evic Bogatyrëv à Moscou pendant l'hiver 1945-1946, chez mes parents qui avaient fait sa connaissance à Prague avant la guerre et l'avaient invité chez eux avec sa femme Tatiana, pendant cette courte période de l'après-guerre où le rideau de fer n'était pas encore tout à fait retombé entre les diplomates et journalistes étrangers et les citoyens soviétiques. J'en avais beaucoup entendu parler par les sœurs de ma mère, qui l'avaient fréquenté à l'époque, et qui en gardaient le souvenir d'un original facétieux, possédant parfaitement le tchèque le plus familier (il devait traduire en russe ce chef-d'œuvre de l'humour populaire pragois qu'est Le brave soldat Chveik), mais le parlant avec un accent russe à couper au couteau, qui donnait involontairement une coloration comique à ses propos. Je l'ai retrouvé une vingtaine d'années plus tard au Congrès du Comité international des slavisants de Prague en 1968 où, avec Roman Jakobson, ils s'étaient retrouvés après trente ans de purgatoire «soviétique », dans l'un des berceaux de leurs débuts communs, et je suis allé ensuite lui rendre visite avec ma tante au château de Dobř́šs, où il était l'invité de l'Union des écrivains tchécoslovaques. Un peu plus tard j'ai brièvement connu aussi son 
fils Constantin, poète et traducteur renommé de poésie allemande, détenu (et, d'après la légende, ayant échappé grâce à son âge à une condamnation à mort pour terrorisme) sous Stalin, dissident proche des familiers de Pasternak, assassiné sur le pas de sa porte dans des conditions suspectes.

Ces quelques mots ne sont peut-être pas inutiles pour situer une personnalité hors pair, dont l'œuvre scientifique, abondante et variée, est longtemps restée dans l'ombre, tant à cause de l'originalité de son domaine de recherches que de celle de sa biographie.

3 Le recueil composé et présenté par Serguei Tchougounnikov et Cécile Trautmann-Waller n'en est pourtant pas la première introduction auprès du lecteur français, puisque c'est en français qu'a d'abord paru l'un de ses principaux ouvrages, Actes magiques, rites et croyances en Russie Subcarpathique, publié en 1929 par l'Institut d'études slaves, et dont ce recueil reprend l'introduction, «La méthode historique et la méthode statique ». C'est un exposé théorique et méthodologique, qui illustre bien l'association constante, dans l'œuvre du savant, des deux versants inséparables de cette œuvre, celui des enquêtes de terrain (particulièrement favorisées par son exil temporaire en Tchécoslovaquie, puisque c'est à ce pays qu'appartenait alors cette région rattachée au lendemain de la guerre à l'Ukraine soviétique), et celui de la réflexion théorique.

C'est en théoricien que Bogatyrëv se rattache, dès ses débuts, au formalisme russe : encore étudiant à l'université de Moscou, il est l'un des fondateurs du Cercle linguistique de Moscou, dont l'association avec l'OPOJAZ, fondé à Saint-Pétersbourg, sera le berceau de l'« école formelle ». Toujours guidé par le matériau concret de sa recherche, il n'est pas de ceux qui donneront à la doctrine ses formulations les plus provocantes et les plus révolutionnaires: son apport théorique, beaucoup moins voyant, prend racine dans la recherche ethnographique, qu'il renouvelle cependant en y introduisant, à partir du modèle linguistique, l'innovation « saussurienne » décisive, substituant l'étude synchronique ("statique», selon sa terminologie) à celle de la genèse historique. C'est la même démarche qui inspire le court essai « À propos de la géographie ethnologique", qui évalue le profit que l'ethnographie pourrait tirer, à l'instar de la linguistique, de la prise en compte du facteur géographique. Aux emprunts à la linguistique structurale et fonctionnelle appartient aussi l'essai établissant une distinction entre faits ethnographiques productifs et improductifs, et entre «faits actifs-collectifs » et " passifs-collectifs ». Des textes plus courts décrivent l'application de la notion fondamentale de structure à l'étude de la chanson populaire et du costume régional. Le plus important au point de vue théorique est le texte écrit en collaboration avec Jakobson sur «Le folklore, forme spécifique de création » qui, en établissant une distinction structurelle fondamentale entre la « création populaire » et la littérature, permet d'aborder de façon plus rigoureuse les relations qui ont toujours existé entre ces deux domaines.

5 Parmi les études qui forment la première partie du recueil, certaines s'attardent sur l'itinéraire scientifique dont ces textes sont les étapes. Ainsi l'article de Klaas-Hinrichs Ehlers, «P.G.B. et le Cercle linguistique de Prague : traces d'une biographie d'émigré » retrace minutieusement son long séjour (de 1922 à 1940) en Tchécoslovaquie, où il a contribué avec son ami Roman Jakobson à féconder les travaux du Cercle linguistique de Prague par l'apport du formalisme russe. Ainsi également, dans une large mesure, l'article d'Andrei Toporkov («Actes magiques, rites et croyances en Russie Subcarpathique (1929) : le contexte russe »), qui met l'accent sur l'impact de son œuvre 
scientifique en URSS où, après plusieurs années de silence dues à la suspicion provoquée par son long séjour à l'étranger, sa redécouverte vers la fin des années 1950 a contribué à la lente réhabilitation du structuralisme, longtemps réputé « bourgeois ».

6 Son œuvre d'ethnographe est évoquée par la brève contribution de Svetlana Sorokina «Les carnets d'expédition de Bogatyrëv » présentant ses méthodes de travail sur le terrain, tandis que Serguei Nekljudov illustre par une étude originale du rite mongol de l'ovoo les distinctions théoriques qu'il a tracées entre faits ethnographiques productifs et improductifs, « faits actifs-collectifs » et « passifs-collectifs » (cf. supra).

7 Plus attachés à l'analyse conceptuelle de son apport théorique sont les articles des deux éditeurs du recueil. Céline Trautmann-Waller s'appuie sur la richesse des références scientifiques de ses nombreux articles pour suggérer la variété des influences qui se sont superposées pour orienter les postulats formalistes de ses débuts vers une sémiotique structurelle et fonctionnaliste. Serguei Tchougounnikov situe sa définition $d u$ « fait ethnographique » par rapport aux doctrines psychologiques de l'époque.

Enfin Veronika Ambros ( P. Bogatyrev et E.F. Burian. Entre formalisme et structuralisme; entre ethnographie et sémiotique du théâtre, entre folklore et théâtre moderne ») et Eva Slaisova (" "Gesunkenes Kulturgut" ? Bogatyrëv et la transformation fonctionnelle des faits ethnographiques ») abordent un domaine original des réflexions de Bogatyrëv, le théâtre, auquel est consacré l'un des textes de la deuxième partie, « Les signes théâtraux »; elles montrent comment les préoccupations théoriques du savant, enrichies par sa fréquentation des milieux d'avant-garde de la capitale tchèque, ont fécondé la culture pragoise contemporaine.

\section{AUTEURS}

\section{MICHEL AUCOUTURIER}

Paris IV 